\title{
ATTEMPTED SUICIDE IN EASTERN B.A.O.R. A COMPARATIVE SURVEY
}

\author{
Major P. E. COPUS, M.A., M.B., D.P.M., R.A.M.C. (T.A.V.R.) \\ 219 (Wessex) General Hospital, R.A.M.C. (V)
}

IN recent years, several large series of civilian attempted suicides have been studied (Stengel, Cook and Kreeger 1958, Tuckman, Youngman and Bleiberg 1962, Kessel 1965). Studies of military personnel are smaller and less numerous, but several published series àre readily available (Pozner 1953, Mitchell 1963, Fisch 1954, Tucker 1967, Offenkratz 1957, Teicher 1947). Suicide, as opposed to attempted suicide, in the armed forces, has been studied generally by Pozner (1953), and statistically for the office of the Surgeon General of the United States Army by Karpinos, whose findings are quoted in Dublin (1963). These studies show that in peacetime, suicide among servicemen is higher than the civilian average, but falls to a low figure during times of war. Most military studies have shown a higher suicide rate for officers, thought to result from their higher average age, and the greater responsibility demanded of them. One observation of Karpinos' is of interest to this present study: the higher military suicide rate is only true of men over the age of 25 years.

Studies of attempted suicide have yet to resolve two major difficulties. Firstly, measuring the exact incidence of attempted suicide in any given population and secondly, assessing the true significance of the act. Parkin and Stengel (1965) in their Sheffield study, looked at three sources of case material in the community, namely the general hospital, the mental hospital, and general practice records of patients treated in surgeries or at home. They acknowledged their inability to assess a fourth source, however; those attempted suicides which never receive medical attention. With this limitation in mind, they estimated an attempted suicide rate some 10 times greater than that for the completed act. Assessing the significance of the suicide attempt had led to a plethora of terminology such as, suicide gesture, self-poisoning and self-injury, and pseudo suicide. Mayer-Gross, Slater and Roth (1969) discuss this topic more fully.

The present study surveys the male attempted suicides referred to the Area Psychiatrist, British Military Hospital, Rinteln, during 1968. The series numbered 25, which is doubtless an underestimate, but likely to be less so than in civilian practice, because the reaction provoked in a compact military unit by a suicidal attempt is such that medical intervention and subsequent psychiatric assessment are almost invariable. The source of the cases was the catchment areas of the British Military Hospitals at Rinteln and Hanover which cover an area of some 10,000 square miles and includes a male adult population of approximately 27,000 .

\section{Method}

The three groups of patients studied were Group 1, 25 attempted suicides, Group 2, 24 psychiatric patients selected by random numbers from the 1968 case-note files, and Group 3, 48 hospital patients who were consecutive admissions with minor traumatic or surgical complaints, and who completed anonymously, a brief biographical questionnaire. This last group was assumed to represent the other-rank population of the area, 
and was used as a control group. There were no officers in the attempted suicide group, so they were excluded from the two other groups. Some statistical comparisons are made, though it is realised that the significance of these is limited by the smallness of the numbers involved.

\section{Results}

In 1968 the total number of first referrals to the clinic of adult male psychiatric patients was 171 , which for a population of 27,000 gives a yearly incidence of 0.63 per cent. The 25 attempted suicides represent 14.6 per cent of these 171 referrals, and equate to an incidence of 92.5 per 100,000 male population.

Table I shows a breakdown of the three groups according to Rank, Age and Length of service. Significant differences exist between Groups 1 and 3 with respect to proportions of Private soldiers, those aged 24 or under, and those having served less than 2 years.

Table II shows the proportions of patients according to marital status, a history of a broken home, or the involvement of alcohol. A "broken home" was defined as one in which one or both parent was lost, or absent as a result of conflict, before the individual reached the age of 17 . The role of alcohol was less easy to establish, and the criteria are different for the three groups. Intergroup comparisons are therefore not valid, and the figures are reproduced for interest. In Group 1 those individuals known

Table I

Breakdown of 3 groups according to rank, age and length of service

\begin{tabular}{l|c|c|c|c|c|c}
\hline & \multicolumn{2}{|c|}{ Group 1 } & \multicolumn{2}{c|}{ Group 2 } & \multicolumn{2}{c}{ Group 3 } \\
\cline { 2 - 6 } & Number & Per cent & Number & Per cent & Number & Per cent \\
\hline $\begin{array}{c}\text { Rank } \\
\text { Junior NCO }\end{array}$ & 22 & 88 & 19 & 76 & 22 & 46 \\
Senior NCO & 3 & 12 & 3 & 12 & 22 & 46 \\
Civilian & - & -1 & 4 & 4 & 8 \\
\hline
\end{tabular}

Groups 1 and 3 compared for proportions in rank of private: Yates $\mathrm{Chi}^{2}-10.5 ; \mathrm{p} \rightarrow 0.01$.

\begin{tabular}{|c|c|c|c|c|c|c|}
\hline $\begin{array}{l}\text { Age } \\
\text { 15-19 years } \\
20-24 \text { years } \\
25-29 \text { years } \\
30 \text { plus years }\end{array}$ & $\begin{array}{r}11 \\
11 \\
3 \\
\end{array}$ & $\begin{array}{r}44 \\
44 \\
12 \\
\end{array}$ & $\begin{array}{r}7 \\
8 \\
3 \\
3 \\
7\end{array}$ & $\begin{array}{l}28 \\
32 \\
12 \\
28\end{array}$ & $\begin{array}{r}7 \\
22 \\
12 \\
7\end{array}$ & $\begin{array}{l}15 \\
45 \\
25 \\
15\end{array}$ \\
\hline
\end{tabular}

Groups 1 and 3 compared for proportions those aged less that 24: Yates $\mathrm{Chi}^{2}-4.7 ; \mathrm{p}-0.05$.

\begin{tabular}{l|r|r|r|r|r|r}
\hline \multicolumn{1}{c|}{ Service } & & & & & & \\
1 year & 4 & 16 & 1 & 4 & 1 & 2 \\
1-2 years & 6 & 24 & 6 & 24 & 1 & 2 \\
2-4 years & 9 & 36 & 9 & 36 & 17 & 35 \\
5-9 years & 6 & 24 & 2 & 8 & 21 & 44 \\
10 plus years & - & - & 7 & 28 & 8 & 17 \\
\hline
\end{tabular}

Groups 1 and 3 compared for proportions serving less than 2 years: Yates Chi $^{2}-13 \cdot 4 ; p-0.001$. 
Table II

Proportions of patients according to marital status, history of a broken home, or the involvement of alcohol

\begin{tabular}{l|c|c|c|c|c|c}
\hline \multirow{2}{*}{} & \multicolumn{2}{|c|}{ Group 1 } & \multicolumn{2}{c|}{ Group 2 } & \multicolumn{2}{c}{ Group 3 } \\
\cline { 2 - 7 } & Number & Per cent & Number & Per cent & Number & Per cent \\
\hline Married & 6 & 24 & 5 & 20 & 23 & 48 \\
Single & 19 & 76 & 20 & 80 & 25 & 52 \\
Broken home & 4 & 16 & 6 & 24 & 11 & 23 \\
Alcohol involved & 8 & 32 & 7 & 28 & 12 & 25 \\
\hline
\end{tabular}

Table III

Method used in suicide attempt and previous suicide attempt known

\begin{tabular}{l|c|c|c|c|c}
\hline \multicolumn{2}{c|}{ Method used in suicide attempt } & \multicolumn{3}{c}{ Previous suicide attempt known } \\
\cline { 2 - 5 } & Number & Per cent & & Number & Per cent \\
\hline Drugs & 16 & 64 & Group 1 & 6 & 24 \\
Cutting & 7 & 28 & Group 2 & $\frac{3}{6}$ \\
Drowning & 1 & 4 & Group 3 & & \\
Traffic accident & 1 & 4 & & & \\
\hline
\end{tabular}

Table IV

Proportion of problems of the 3 Groups

\begin{tabular}{l|c|c|c|c|c|c}
\hline \multirow{2}{*}{ Problém } & \multicolumn{2}{|c|}{ Group 1 } & \multicolumn{2}{c|}{ Group 2 } & \multicolumn{2}{c}{ Group 3 } \\
\cline { 2 - 6 } & Number & Per cent & Number & Per cent & Number & Per cent \\
\hline Situational & 16 & 64 & 12 & 48 & 19 & 40 \\
Sex & 4 & 16 & 6 & 24 & 10 & 21 \\
Not known & 5 & 20 & 7 & 28 & - & - \\
\hline
\end{tabular}

to have been drinking heavily prior to the attempt were included; in Group 2, those who themselves complained of a drinking problem or were reported by their units as drinking excessively; and in Group 3, those patients who assessed themselves on the questionnaire as drinking more than was good for them.

In Table III the interesting feature is the relative lack of variation in the methods chosen-over 90 per cent involved just two methods. Firearms are conspicuous by their absence, which may be related to the control and supervision of live ammunition in military units. Also in Table III, of the six attempted suicides who had made previous attempts, four were suffering from some material psychiatric disability.

Although the information in Table IV was obtained by different methods, (by interview in Groups 1 and 2, and questionnaire in Group 3) there is little difference in the proportions of the three groups. The term "situational" was used to describe problems of adjustment with family or Army, rather than the alternative subdivision of 'Army' and 'Family' because so often a dislike for service life was related by the subject to anxiety about family problems. These were considered to have become intolerable, even though, in many cases, these same family problems had prompted him to enlist. Apart from this general environmental category, the majority of other anxieties related to sexual adjustment. 
As can be seen from Table V, the majority of the attempted suicide group showed no material psychiatric disability, but most of these were considered to have shown marked "immaturity reactions" at the time of their attempt. That is, their behaviour was " acting-out" and regressive, though normally their personalities were well integrated. The three exceptions to this showed spurious attempts which were consciously manipulative in their motivation. In the table, six cases bad multiple diagnoses, (most commonly a psychosexual disorder with a concomitant affective reaction) so the figures in each column summate to more than 25 .

Table V

Diagnosis of attempted suicide and psychiatric patients

\begin{tabular}{|c|c|c|c|c|}
\hline \multirow{2}{*}{ Diagnosis } & \multicolumn{2}{|c|}{ Attempted suicide } & \multicolumn{2}{|c|}{ Psychiatric patients } \\
\hline & Number & Per cent & Number & Per cent \\
\hline $\begin{array}{l}\text { No material psychiatric disability } \\
\text { No material psychiatric disability- } \\
\text { immaturity reaction } \\
\text { Personality disorder: Immature } \\
\\
\begin{array}{l}\text { Psychopathic } \\
\text { Schizoid }\end{array} \\
\begin{array}{l}\text { Psychosexual } \\
\text { Depressive reaction }\end{array} \\
\text { Anxiety reaction } \\
\text { Schizophrenia } \\
\text { Alcoholism } \\
\text { Others }\end{array}$ & $\begin{array}{r}3 \\
10 \\
4 \\
2 \\
2 \\
2 \\
4 \\
- \\
- \\
-\end{array}$ & $\begin{array}{r}12 \\
40 \\
16 \\
8 \\
8 \\
8 \\
16 \\
- \\
- \\
-\end{array}$ & $\begin{array}{l}3 \\
7 \\
1 \\
1 \\
1 \\
2 \\
3 \\
2 \\
4 \\
5\end{array}$ & $\begin{array}{r}12 \\
28 \\
4 \\
4 \\
4 \\
8 \\
12 \\
8 \\
16 \\
20\end{array}$ \\
\hline
\end{tabular}

Nearly half of the Attempted Suicide patients were admitted directly to hospital as medical emergencies and only subsequently assessed psychiatrically (Table VI). Of the 15 referred to the out-patient clinic, only one-fifth needed admission to hospital. These proportions differ considerably from the corresponding figures for Psychiatric Patients. Of the 25 patients in the Attempted Suicide group, 23 were returned to their Units after in, or out-patient care, and the majority of these required no change in their medical category.

Table VI

Proportion of patients in Groups 1 and 2 returned to their units after hospital treatment with assessment of medical category

\begin{tabular}{|c|c|c|c|c|}
\hline \multirow[t]{2}{*}{ v } & \multicolumn{2}{|c|}{ Group 1} & \multicolumn{2}{|c|}{ Group 2} \\
\hline & Numbers & Per cent & Numbers & Per cent \\
\hline $\begin{array}{l}\text { Type of admission } \\
\text { Immediate hospitalisation } \\
\text { Referred for out-patient appointment } \\
\text { Admitted to hospital after psychiatric } \\
\text { examination }\end{array}$ & $\begin{array}{r}10 \\
15 \\
3\end{array}$ & $\begin{array}{l}40 \\
60 \\
12\end{array}$ & $\begin{array}{r}3 \\
22 \\
9\end{array}$ & $\begin{array}{l}12 \\
88 \\
36\end{array}$ \\
\hline $\begin{array}{l}\text { Returned to unit } \\
\text { Pulheems unchanged } \\
\text { Pulheems reduced } \\
\text { Recommended for discharge on psychiatric } \\
\text { grounds }\end{array}$ & $\begin{array}{r}17 \\
6 \\
5\end{array}$ & $\begin{array}{l}68 \\
24 \\
20\end{array}$ & $\begin{array}{r}10 \\
8 \\
3\end{array}$ & $\begin{array}{l}40 \\
32 \\
12\end{array}$ \\
\hline
\end{tabular}




\section{Discussion}

The proportion of male psychiatric first referrals presenting as attempted suicides was nearly 15 per cent, a figure similar to that reported in the United States Services (Fisch 1954, Tucker and Gorman 1967). The estimated incidence in the present study is 92.5 per 100,000. The Registrar General's Statistical report for England and Wales (1967) estimates that 994 males between the ages of 15 and 45 committed suicide out of a corresponding population of 9,796,000. Applying Stengel's factor of 10 to the resulting incidence, one obtains a figure of 101 attempted suicides per 100,000 population. The incidence in the present study is thus slightly lower than the corresponding civilian rate the previous year. Mitchell (1963) estimated an incidence of 390 per 100,000, but this number takes into account those threatening suicide, or talking about it, a group not considered in the present study. The high proportion of junior ranks shown in Table $\mathrm{I}$ is in keeping with the 80 per cent reported by both Fisch (1954) and Offenkrantz (1957), but in excess of Pozner's figure of 64 per cent. The latter author also found a much higher proportion of commissioned officers ( 28 per cent) than the other series. With regard to age, nearly all the military series surveyed show a preponderance of young men, with mean ages ranging up to 22 years. This is in contrast to British and American civilian studies which when prorated for an age range of 15-49 years, show mean ages of around 30 years (Whitlock and Schapira 1967, Batchelor and Napier 1954). As might be anticipated from the age and rank findings, the length of service of the attempted suicides in the present series tends to be short, and a breakdown of the 40 per cent who have served less than two years shows a mean time marginally less than 13 months. If a period of 6 months is allowed for initial training, this means that a large proportion have made their attempt within 7 months of arrival in their first " foreign" (geographically if not administratively) posting. Offenkrantz (1957) found that 62 per cent of his series' had threatened or attempted suicide within the first two years, and both Mitchell (1963) and Pozner (1953) reported large proportions making their attempt within the first year.

The 26 per cent of Group I who were married corresponds closely to the 24 per cent in Tucker and Gorman (1967) series. It differs from the finding of Mitchell (1963) who reported that proportionately more of his suicidal group were married, as did Offenkrantz (1957). The significance of a broken home in the aetiology of attempted suicide has received considerable attention. Greer, Gunn and Koller (1966) in their series from Kings' College Hospital found that their attempted suicide group contained a higher proportion of individuals from broken homes than did their comparable psychiatric and general patient groups. The present series did not show this difference. The significance of alcohol in attempted suicide has been emphasised by several authors, with a high incidence of heavy drinking just prior to the attempt, Whitlock and Schapira (1967) reporting 60 per cent and Kessel (1965) 56 per cent. The figure of nearly one-third in the present series is strikingly modest in comparison with the above percentages, and also in the light of one's impression of the drinking habits of the younger servicemen. In the context of attempted suicide in the younger age group, one could argue that alcohol just prior to an attempt serves either to impart "Dutch courage" for what is potentially a painful and even hazardous venture, or to act as a cortical depressant disinhibiting aggressive behaviour already latent.

The method used in the attempt has received attention in nearly all studies. The two most common methods are lacerating self-injury and drug ingestion. In American 
military series self-laceration predominates, whereas British military studies, like the present one, are in keeping with more recent United Kingdom (U.K.) and United States of America (U.S.A.) civilian studies which show drug-ingestion to be the method of choice; in Tuckman, Youngman and Bleiberg (1962) 46 per cent, in Whitlock and Schapira (1967) 91 per cent, and in Parkin and Stengel (1965) 80 per cent. In view of the presumably aggressive personality of the fighting man, this choice by British soldiers of the less violent of the two methods, is perhaps surprising. Apart from being violent, selflaceration tends to be an ineffectual method of killing oneself. Fisch (1954) in his United States Army series showed a reversal of methods between his attempted and successful suicide groups. Thus of the attempts, 50 per cent cut themselves, mostly wrists and arms, and 4 per cent used firearms, whilst in the successful group, 43 per cent used firearms and only 6 per cent used self-laceration, all of the throat. The absence of firearms in the present series has already been commented upon. Bizarre methods should always raise the possibility of a psychotic illness. Although the present series contains no such case, a year previously a schizophrenic soldier had first severly lacerated himself, then poured whisky over his body and set fire to it.

Problems of sexual adjustment were thought to be an important factor in attempted suicide by Tucker and Gorman (1967) who found that 55 per cent of his group had marked anxieties in this field, a significantly higher proportion than in his two comparison groups of non-suicidal patients. In the present series, individuals in Group 1 admitting to sexual anxieties, whether concerning heterosexual competence or homosexual conflicts, were less numerous than in Groups 2 and 3 (Table IV). Furthermore it was only occasionally that there appeared to be a direct relationship between an individual's sexual anxiety and his suicide attempt.

The breakdown of diagnoses in Table $\mathrm{V}$ shows that the two major categories were Personality Disorder (40 per cent) and No Material Psychiatric Disability (52 per cent), the majority of the latter being classified as "Immaturity Reactions". Serious mental illness in Group 1 was rare. The U.K. military series are unanimous in finding a preponderance of personality disorders, and in the proportion they consider normalMitchell (1963) Pozner (1953) and the present study, all quoting 12-13 per cent. Nearly all of the other studies surveyed showed a similar preponderance of personality disorders, though as the age of the sample rises, such as Schmidt, O'Neal and Robins (1954) with a mean age of 44.7 years, so does the incidence of organic and functional mental illness: The approack of civilian authors to the " normal " attempted suicide is interesting, and there is reluctance to call them normal. Schmidt, O'Neal and Robins provide a category of "Undiagnosed" for those who "failed to reach the minimal criteria for each diagnostic category" and Batchelor and Napier (1954) includes them in "Others", ranging from near psychopathic to " near normal". Kessel (1965) however, puts 26 per cent in his No Psychiatric Illness category and points out that "distress drives people to self-poisoning acts, and distress is not the exclusive province of the mentally ill ". Greer, Gunn and Koller (1966) qualify their No Psychiatric Illness group (11 per cent) with "Acute Situational Reaction ", a concept similar to the "Immaturity Reaction" used in the present study.

Approaches to the problem of disposal are various. Fisch (1954) considered that attempted suicide in " immature and disordered personalities" was important because of the risk of repetition. In his group, such personalities amounted to 95 per cent 
and of these " virtually none was returned to duty, who did not want to go, unless he was a prisoner facing a serious charge". Offenkrantz (1957) on the other hand, made it his thesis that, having first excluded those with psychotic or significant depressive symptomatology, one could expect the remainder of attempted suicide patients to show "historical evidence of crudely manipulative or deliquent behaviour", the attempt itself being an extension of this behaviour and a method of "emotional blackmail" which should not be allowed to achieve the manipulation for which it was intended: Most authors have used an approach more similar to Offenkrantz's. Pozner (1953) admitted 32 per cent of his group to hospital, but returned the remainder to their units, 21 per cent with no alteration in Pulheems, 28 per cent downgraded, and a further 19 per cent recommended for medical discharge S8. Tucker and Gorman (1967) admitted to their treatment centre 3 per cent of their series, boarded 20 per cent, and returned 83 per cent to duty, 60 per cent with no change of medical category. They followed up their series just over one year later and found that of the patients they had returned to duty, 48 per cent had been discharged on administrative grounds. In the present series, a policy of returning to duty was followed wherev'er possible. Only 2 of the 25 were not ultimately returned to their unit, but were transferred to the Command Psychiatric Unit, and a further 20 per cent returned to their Units pending a Medical Board.

Although six of the present group had made attempts before, only one was known to have repeated his attempt after the current assessment, though it must be said that the cases were not individually followed up for this purpose. No recurrence rates were found in the available military series, so civilian studies have to be consulted to obtain some idea of the frequency. The methodological problems in such studies are formidable, and it is difficult to apply the results to a service population because both sexes are included and the age range of the population is much wider. However, it seems likely that about 5 per cent of attempted suicides are repeated in each year of follow-up, and that up to 1 per cent of an attempted suicide group will kill themselves in each succeeding year. In a large study, Tuckman and Youngman (1963) in Philadelphia found that of 1112 attempted suicides, 16 had repeated the act successfully one year later. Various attempts have been made to formulate methods for identifying the individuals who are likely to become successful suicides. There are no hard and fast criteria, but guide-lines can be drawn up; the high-risk cases have certain features in their backgrounds including higher age, social isolation and physical illness. Psychiatric illness, particularly psychosis and organic dementia, is always a danger sign. In most series, the patients making the successful repeats have a mean age well above that of the attempted suicide groups in military studies. Fisch (1954) points out that the patient who is unable to verbalise his aggression and grievances is potentially more dangerous than the one who has a long list, readily recited. The details of the attempt, with attention to the likelihood of success, are also helpful pointers, as are the patient's feelings and attitudes at the time, guilt and unworthiness always indicating that the attempt be taken seriously.

A major problem remaining is why the individual attempts suicide rather than using other forms of manipulation, or reacting with some form of mental illness. Rubinstein, Moses and Lidz (1958) have drawn attention to the possibility that verbal methods of communication would tend not to be used in individuals of lower socioeconomic status, because actions are considered more valuable than words, in the use of which they are disadvantaged. They go on to argue that attempted suicide can also be more satisfying in having, like other forms of acting-out, a spiteful aspect, so that: by. 
hurting himself the individual mobilises the latent aggressions and guilt-feelings of those in his environment, who, in the case of the soldier, are seen as "the implacable impersonal authority of the Army, the surrogate father figure" (Pozner 1953). In-many cases, the soldier is continuing against this father figure a rebellion started many years previously. There is a new factor in the soldier's present situation however, which is the "implaccable" authority of the Army from which he feels, perhaps for the first time, unable to escape. The new factor has in effect nullified the effectiveness of the individual's previous life-style, causing him to resort to the more desperate solution of attempted suicide. This concept of breakdown of life-style precipitating suicide attempts has been expanded more fully by Roberts and Hooper (1970).

\section{Conclusion}

The present study, and the others reviewed, support the impression that there is a group of young, impulsive individuals, mentally well if immature, who attempt selfinjury as a means of manipulating what they consider to be an intolerable environment. Their attempts have what Kessel (1965) describes as "a significant correlation with the likelihood of survival ". These attempts can be regarded as maladaptive responses which should not be reinforced if at all possible. It is better to attempt to rehabilitate these individuals rather than discharge them, for a variety of psychiatric reasons, quite apart from the military consideration of conserving manpower. One reason, avoiding reinforcement of a maladaptive response, is given above. Another is that the patient's biography frequently shows persistently poor adjustment to changing circumstances, and his enlistment has often been an attempt to find a solution to his problems. In many ways he has made a good choice, with an environment which offers him dependence, corporate identification, an acceptable outlet for his poorly controlled aggressivity, and structured control. It is the last which is the stumbling block, whose inevitably authoritarian expressions overwhelm the individual's low tolerance, and cause him to resort again to manipulating his environment rather than using internal, adaptive mechanisms. This latter aspect should receive the attention of the physician, who should attempt to help the patient develop better adaptive responses, in other words to " mature". This is no easy task, success rates will not be high, and even if psychiatric discharge is avoided, fall-out is appreciable, as Tucker and Gorman (1967) have shown. But at least this fall-out is on administrative grounds, and the physician has avoided colluding in the myth of psychiatric illness which the patient has projected by his behaviour. It must be emphasised that in refusing to collude, the physician is not rejecting the patient, on the contrary, he must show that the latter's " cry for help" is receiving sympathetic attention, and that satisfactory solutions to his problems do exist. The group of individuals to whom the above remarks apply are characterised by their youth, junior rank, brief service time, unmarried status, and the absence of significant mental or physical illness. The present study, and the majority of those surveyed, show that it is possible to return to their Units such individuals who have attempted suicide, without undue risk of mortality or further morbidity. In the present series, the characteristics of the attempted suicide group did not differ from those of the psychiatric patient group, except with regard to diagnosis.

\section{Acknowledgements}

I would like to thank Brigadier J. F. D. Murphy for his encouragement and advice in the preparing of this paper, and to Mrs. Janet Almond for her invaluable assistance in selecting and processing the original case material. 


\section{REFERENCES}

BATChelor, I. R. C. and NAPIER, M. (1954). J. Neurol. Psychiat. 17, 261.

Dublin, L. I. (1963). Suicide-A Sociological and Statistical Study. New York.

Fisch, M. (1954). Amer. J. Psychiat. 111, 33.

Greer, S., GuNN, J. C. and Koller, K. M. (1966). Brit. med. J. ii, 1352.

KESSEL, N. (1965). Brit. med. J. ii, 1265.

MAYeR-Goss, W., SLATER, E. and Roth, M. (1969). Clinical Psychiatry. 2nd ed. Cassell. London.

Mitchell, A. R. K. (1963). J. roy. Army med. Cps. 109, 215.

OfFenkrantz, E. (1957). Amer. J. Psychiat. 114, 33.

Parkin, D. and Stengel, E. (1965). Brit. med. J. ii, 133.

POZNer, H. (1953). Brit. J. med. Psychol. 26, 93.

ROBERTS, J. F. and HOOPER, D. (1970). Brit. J. med. Psychol. 42, 303.

Rubinstein, R., Moses, R. and Lidz, T. (1958). Arch. Neurol. Psychiat.(Chic.) 79, 103.

SCHMIDT, E. H., O'NeAL, P. and Robins, E. (1954). J. Amer. med. Ass. 155, 549.

Stengel, E., CooK, N. G. and KREEGER;' I. S. (1958). Attemtped Suicide. Maudsley Monogr. No. 4. London.

TEICHER, J. D. (1947). J. nerv. ment. Dis. 105, 283.

TUCKRR, G. J. and GORMAN, E. R. (1967). Amer. J. Psychiat. 123, 854.

Tuckman, J., Youngman, W. F. and BleiBerg, B. M. (1962). Publ. Hlth Rep.(Wash.) 77, 605.

Tuckman, J. and Youngman, W. F. (1963). Publ. Hlth Rep.(Wash.) 78, 763.

Whitlock, F. A. and SchapIRA, K. (1967). Brit. J. Psychiat. 113, 423.

\section{Appointment to the Queen}

Colonel J. J. Voller, M.R.C.S., L.R.C.P., F.F.A.R.C.S., Late R.A.M.C., has been appointed Honorary Physician to The Queen.

\section{Honorary Consultant}

Mr. John Winstanley, M.C., T.D., M.B., F.R.C.S., has oeen appointed Honorary Consultant in Ophthalmology to the Army at Home, with effect from 12 July 1971. 